\title{
Analysis of eAGRI Web Portal Ergonomics And Presentation of Information in Terms of the General Public
}

Petr Benda, Pavel Šimek, Jan Masner, Jiří Vaněk

Faculty of Economics and Management, Czech University of Life Sciences Prague, Czech Republic

\begin{abstract}
The aim of the eAGRI portal is to inform not only professionals in the field of agriculture but also the general public about current events and news in the respective resort. Merit of the paper is to discover if the current level of eAGRI portal ergonomics is sufficient or not. Several usability analysis and studies were applied with unflattering results. The results of all applied analysis show that the overall ergonomics of the portal is not at a satisfactory level and that there is no significant improvement on the portal in the last year.
\end{abstract}

\section{Keywords}

Ergonomics, Usability Analysis, eAGRI portal, Human-Computer Interface, Five second test, Thirty second test, Heuristic evaluation, First click test.

Benda, P., Šimek, P., Masner, J. and Vaněk, J. (2017) “Analysis of eAGRI Web Portal Ergonomics And Presentation of Information in Terms of the General Public", AGRIS on-line Papers in Economics and Informatics, Vol. 9, No. 4, pp. 3-13. ISSN 1804-1930. DOI 10.7160/aol.2017.090401.

\section{Introduction}

The eagri.cz web portal is the central access point to the information sources of the Ministry of Agriculture and its deputy organizations (Ministry of Agriculture CR, 2015a). Therefore it is appropriate to analyze the ergonomics of the eAGRI portal in terms of the general public to which the community of agricultural professionals belongs.

The word "Ergonomics" is currently widely used among people. In terms of draft recommendations in ergonomics of an average web portal it is necessary to analyze current state of this portal first. This can be realized by using specific User Experience (UX) or Usability methods on which it is then possible to formulate appropriate recommendations. Terms like usability and UX are used mainly by computer science professionals and those are not well known to the general public. So, how Ergonomics is related to those terms?

The term Ergonomics came into use about 1950 when the priorities of developing industry were taking over from the priorities of the military. The development of research and application for the following thirty years is described in detail in Singleton (1982), where the Ergonomics is defined as the study or measurement of work. In this context, the term work signifies purposeful human function it extends beyond the more restricted concept of work as labor for monetary gain to incorporate all activities whereby a rational human operator systematically pursues an objective. Thus it includes sports and other leisure activities, domestic work such as child care and home maintenance, education and training, health and social service, and either controlling engineered systems or adapting to them, for example, as a passenger in a vehicle.

IEA (2017) and ISO 6385:2016 (2016) define the modern Ergonomics as the scientific discipline concerned with the understanding of interactions among humans and other elements of a system, and the profession that applies theory, principles, data and methods to design in order to optimize human well-being and overall system performance. Ergonomics is a systems-oriented discipline which now extends across all aspects of human activity. Practicing ergonomists must have a broad understanding of the full scope of the discipline. That is, ergonomics promotes a holistic approach in which considerations of physical, cognitive, social, organizational, environmental and other relevant factors are taken into account.

In modern era, with the arrival of computers, Ergonomics also targets the Human-Computer Interaction (HCI). Until late 1970s, no one could interact with computers except for computer experts. This situation changed entirely 
after personal computing, including both personal software and personal computer platforms, was developed, which turned everybody into a potential computer user (Carrol and Rosson, 2009). Rogers (2012) states that HCI at the beginning followed the scientific method borrowing theories from cognitive science to test theories about user performance at the interface. Carrol (2003) adds that Human-Computer Interaction combines several different disciplines, each of which focuses on a different aspect of creating user interfaces. These disciplines include information science, psychology, sociology, anthropology, design, linguistics, ergonomics, and all other disciplines that focus on the subject. Zhang and Li (2005) see that with the rapid growth of information systems and communication technology, information technology has come to play a central role in daily lives. Issues regarding the interaction between humans and computers have thus become important and fundamental.

The cooperation between designers, engineers and scientists in the Human-Computer Interaction (HCI) community is often difficult, and can only be explained by investigating the different paradigms by which they operate (Bartneck and Rauterberg, 2007). Rusu, et al. (2015) describe HCI from multiple perspectives, when HCI should be a basic part of the formative process of all Computer Science (CS) professionals. Usability and User Experience (UX) were (re)defined by many authors and well recognized standards. UX is usually considered as an extension of usability. To move from usability to UX seems to be a tendency lately. The lack of generally agreed formal definitions of $\mathrm{HCI} /$ usability/UX may have consequences on their development and recognition among Computer Science communities.

All those terms are met and described within the term Human-Centred Design (HCD) which has its roots in fields such ergonomics and computer science (Giacomin, 2014) and it is standardized by ISO 9241-210:2010 - Ergonomics of Humansystem interaction — Part 210: Human-centred design for interactive systems. New important ISO document about "Usability: Definitions and concepts" is still under development (ISO/FDIS 9241-11, 2017).

Based on the presented information we can conclude that the concept of Ergonomics, which is often referred by the general public as a key element of interaction with the computer or e.g. the web portal, is too wide. For the purposes of this article, it is necessary to focus especially on the identified components of Ergonomics, such are UX and Usability.

According to ISO 9241-210:2010, the User Experience (UX) can be defined as the perception and reaction of persons resulting from the use or assumption of use of a given product, system or service. Usability is understood as a part of UX and subsequently as part of Human-Centred Design concept. The Usability itself is defined by ISO 9241-11:1998 that is used in subsequent related ergonomic standards as the extent to which a product can be used by specified users to achieve specified goals with effectiveness, efficiency and satisfaction in a specified context of use. Expert on Website Design and Usability Steve Krug (2006) formulated three basic facts about user behavior:

- We do not read pages, but browse;

- We do not make optimal selections, but compromise;

- We do not worry about how things work, we simply "do somehow".

The website should be intuitive, understandable and navigable. In any case, the user should not think about where to start navigating the site, where he finds what he is looking for, or what's important on the page. The most visited pages are those that are simple, clear and intuitively manageable (Krug, 2006; Nielsen, 1993). Designers must understand the effects of their designs on users' choices so they can choose whether to implement a design that nudges users deliberately or one that reduces the effects of the design on users' choices in order to increase free will (Weinmann et al., 2016).

\section{Materials and methods}

Some usability studies of eAGRI portal, such are Benda, et al. (2016) and Ulman, et al. (2017) has been implemented already in 2016 and early 2017. This paper therefore uses the same usability methods to maintain comparability of results. However, the subject of investigation itself is slightly expanded. Specifically, these usability tests are: Five Second Test, Thirty Second Test and Heuristic evaluation. Currently performed test is a First Click test. An important data input and analysis was also performed by Google Analytics. Five Second Test and Thirty Second Test were, compared to the above-mentioned studies, slightly widened.

\section{Five second test}

Five second test can help increase website conversion and improve Return of Investments (ROI). Five seconds is a time for a website visitor to determine if there is enough quality in a website 
to stay, or to leave and potentially never to return. Using a Five second test to optimize conversion is a powerful way to improve the ROI of a website. This is because the critical driver of website success is the ability of the home page, or any page for that matter, to deliver three pieces of critical information in five seconds or less. The first piece is delivering information about the website - What is it about. The second one describing the information what product or service the website provides. The third one informing user why to stay and continue the navigation thru the web, so - what user able to find and use on the website (Tomlin, 2014).

Lindgaard et al. (2006) conducted a study to determine how quickly people decide whether they like or dislike what they see, and whether such judgments may constitute a mere exposure effect. The data suggest that a reliable decision is going to be be made in $50 \mathrm{~ms}$, which supports the contention that judgments of visual appeal could represent a mere exposure effect. The level of agreement between participants and between experiments was impressive and highly correlated even for the $50 \mathrm{~ms}$ condition.

Websites that are able to quickly and efficiently communicate these three critical elements within 5 seconds typically have much better conversion, and thus ROI than websites that do not (Tomlin, 2014). As well as Doncaster (2014) and Benda et al. (2016), we used this kind of test to ask users whether they know where they are and let them to simply describe what they saw and are able to find on the portal. So, to collect all three pieces of critical information for users described by Tomlin (2014).

\section{Thirty second test}

This method was used by Benda et al. (2016). The main goal of this method is to follow the Five second test and enable users to scroll and navigate the home page or landing page of the website briefly and get more detailed information about the portal. Then ask users the same questions like after the Five second test.

\section{Heuristic evaluation}

A heuristic evaluation is a usability inspection method for computer software that helps to identify usability problems in the user interface (UI) design. It specifically involves expert evaluators examining the interface and judging its compliance with recognized usability principles - the "heuristics" (Nielsen, 1993). A heuristic evaluation should not replace usability testing. Although the heuristics relate to criteria that affect usability of tested, the issues identified in a heuristic evaluation are different than those found in a usability test (Molich and Nielsen, 1990).

Usability principles and heuristics by Nielsen (1993):

- Visibility of system status - The system should always keep users informed about what is going on, through appropriate feedback within reasonable time.

- Match between system and the real world The system should speak the users' language, with words, phrases and concepts familiar to the user, rather than system-oriented terms. Follow real-world conventions, making information appear in a natural and logical order.

- User control and freedom - Users often choose system functions by mistake and will need a clearly marked "emergency exit" to leave the unwanted state without having to go through an extended dialogue. Support undo and redo.

- Consistency and standards - Users should not have to wonder whether different words, situations, or actions mean the same thing. Follow platform conventions.

- Error prevention - Even better than good error messages is a careful design which prevents a problem from occurring in the first place. Either eliminate error-prone conditions or check for them and present users with a confirmation option before they commit to the action.

- Recognition rather than recall - Minimize the user's memory load by making objects, actions, and options visible. The user should not have to remember information from one part of the dialogue to another. Instructions for use of the system should be visible or easily retrievable whenever appropriate.

- Flexibility and efficiency of use - Accelerators -- unseen by the novice user -- may often speed up the interaction for the expert user such that the system can cater to both inexperienced and experienced users. Allow users to tailor frequent actions.

- $\quad$ Aesthetic and minimalist design - Dialogues should not contain information which is irrelevant or rarely needed. Every extra unit of information in a dialogue competes with the relevant units of information and diminishes their relative visibility. 
- Help users recognize, diagnose, and recover from errors - Error messages should be expressed in plain language (no codes), precisely indicate the problem, and constructively suggest a solution.

- Help and documentation - Even though it is better if the system can be used without documentation, it may be necessary to provide help and documentation. Any such information should be easy to search, focused on the user's task, list concrete steps to be carried out, and not be too large.

\section{First click Test}

This type of test examines what a user would click on first on the interface in order to complete their intended task. It can be performed on a functioning website, a prototype or a wireframe. It is also important not only to find where user clicked, but also to ask the user "Why?" (Sauro, 2011; Geisen and Bergstrom, 2017). The results obtained in this way are also appropriate to compare with the real potential of the website and to find out whether the requested information can actually be found using the executed click.

\section{Analysis of Google Analytics data}

Google Analytics provide digital analytics tools to analyze data from all touchpoints in one place, for a deeper understanding of the user experience. It offers free and enterprise analytics tools to measure website, app, digital and offline data to gain customer insights (Google, 2017).

For the purposes of this study Ministry of Agriculture of the Czech Republic gave us an access to the online data provided by the Google Analytics service.

\section{Results and discussion}

Unlike the order described in the Materials and methods chapter we would like to begin with a results of the analysis, which delivers relevant data and results from the behavior of eAGRI portal users. Access to the Google Analytics data gave us a comprehensive view to facts about the use of eAGRI portal by the real users in the real time.

\section{Analysis of Google Analytics data}

Ministry of Agriculture of the Czech Republic allows us to analyze data provided by the Google Analytics service. We focused on data proposed by the account which collects data from the whole eAGRI portal. We provide only a comprehensive description for the purposes of this paper.
The presented data are therefore only approximate. The reason for using this approximate data is to support the results of further analysis within the study also by the real qualitative data. All analyzed data refer to the period 1.1.2017 23.6.2017.

The average download speed of eAGRI is 1.92 seconds. Google understands this value as below average, especially it is given that the portal is not optimized for speed. This can be achieved by optimizing images, compressing source code, browser caching, and eliminating JavaScript scripts and CSS styles that block page rendering.

The average visit duration is about 3 minutes and on average, users visit 4 web pages per one visit. $50 \%$ of users use Internet Explorer as a web browser, almost $27 \%$ Chrome and almost $15 \%$ Firefox. All other results of browsers are beneath $4 \%$. Just about $6 \%$ of users use mobile phone or tablet to browse the portal.

Within the measured time period more than 11700000 views of web pages were shown to the users on the eAGRI portal. Almost $11 \%$ of all views is dedicated for a home page. The second one with almost $7 \%$ is a web page which allows professional users of the portal to $\log$ in to the internal farming applications called "the Farmer's portal" - eagri.cz/ssl/web/mzel farmar. The third one with about $5 \%$ of all visits is a web page really close to the previous one. This web page provides information about internal farming applications and also contains a direct link to $\log$ in to such applications which was presented as an URL (Uniform Resource Locator) in previous sentence. We realized by the further research of data that user are not staying on this web page for long, just about a few seconds and then click mentioned link to $\log$ in the applications. The fourth web page - eagri.cz/ssl/web-mze with the result of almost $4 \%$ of all views was just another link to internal applications which allows users to sign in. The fact that the site contains more than one URL which refers to the same result is not only significant usability problem, but also problem of possible Search Engine Optimization (SEO).

The fifth web page viewed by user visits in about $2 \%$ is an internal Search tool provided by eAGRI portal. All other results are beneath $2 \%$. It is obvious that the eAGRI portal is used by professional users which want to sign to the internal part of a portal in about $16 \%$. The most views of user visits are dedicated to the home page of a portal in $11 \%$ and about $2 \%$ of views users spent on search tool.

The analysis of eAGRI portal landing page visits 
shows very similar data. There were more than 3 million visits during the measured time period overall. Almost 33\% represent a home page landing visits. Three other pages with almost $25 \%$ of visits together were dedicated to "the Farmer's portal":

- eagri.cz/public/web/mze/farmar;

- eagri.cz/ssl/web/mze/farmar;

- eagri.cz/ssl/web/mze/.

This number also represents a fact that almost $25 \%$ of users are looking for an internal applications directly for their first visit and thus the first use of a portal for their purposes. All other results are beneath $2 \%$ and moreover out of the top positions of those $2 \%$ are other direct URLs to other internal applications such are LPIS (Land Parcel Identification System) and UKZUZ (engl. - Central Institute for Supervising and Testing in Agriculture). It all means that nearly $30 \%$ of the first user visits of the portal target internal applications, thus almost $30 \%$ of landing pages refer to agrarian professionals and their needs.

Interesting results are also presented by the Acquisition Overview analysis. The Acquisition Overview provides a quick view of the top channels sending visitors to the portal, as well as the associated acquisition, behavior and conversions details for each channel. Slightly over $37 \%$ of visits come from Referral traffic source. It means that more than $37 \%$ of visits coming to the portal from another website by clicking on a link. Almost $32 \%$ of visits come from Organic Search channel, thus $1 / 3$ of traffic refers to the results of search engines. Almost the same amount of users come Direct. Those are visitors who come to the portal without a traceable referral source, such as typing direct portal URL into their address bar or using a bookmark on their browser. Just about $1 \%$ of users come from Social Networks and less than a $0.02 \%$ of visits come from Email.

It follows from the above that the main source of eAGRI traffic is dedicated to the visits from other websites. Specifically, from about $84 \%$ this is ilogin.mze.cz. This means, amongst other, that these visits also come from sites provided by Ministry of Agriculture of the Czech Republic, but outside the structure of the eAGRI portal. And it means again, that the most traffic aims to the internal eAGRI application for professionals.

Deeper analyzes of Organic Search source show that almost $68 \%$ of Organic Search is not available in Google Analytics. The second most commonly used key word is with more than $9 \%$ "the Farmer's portal" and then with a little more than $1 \%$ the keyword "LPIS". Other analyzes show that about 665 thousand visits are attributed to the Google search engine and about 271 thousand the Seznam.cz Search Engine. The third search engine is Bing with about 37 thousand visits. Other search engines are only in the level of thousands.

Most often direct entry URL is with almost $78 \%$ the default eAGRI web page. The second page is "the Farmer's portal" but only with a little more than $1 \%$.

Traffic from Social Networks, which generates only about $1 \%$ of all visits, falls to Facebook in almost $98 \%$, when almost $49 \%$ of the traffic comes to a page eagri.cz/public/web/mze/tiskovy-servis/aktualne/ samosber-jahod-prehled-po-krajich-1.html, at the same time it is the most widely used landing page of the eAGRI portal from Social Networks, the other is with $6 \%$ eagri.cz/public/web/mze/ ministerstvo-zemedelstvi/volna-pracovni-mista/. The next is Twitter with only about $1 \%$. Other social networks are about a tenth of a percent.

The lowest attendance is reported by the "Email" medium. According to the results, those visits targeted mainly at http://eagri.cz/public/web/ vinarsky-zakon/. Most traffic then falls into the first week of March 2017.

\section{Analysis of Google Analytics data - summary}

The above-described analysis of Google Analytics data emphasizes several facts that should be at least perceived by portal provider. Only $7 \%$ of users use mobile devices to use the portal. Nowadays eAGRI portal does not offer any type of responsive design. Therefore, it is not entirely clear whether this percentage is so low, because the portal is very difficult to use on these devices, or if that percentage of users with this kind of device is really so low. StatCounter global stats (2017a) reports that average use of mobile device in the Czech Republic in last 12 month is $18.96 \%$, tablet $2.95 \%$ and the desktop rules with $78.09 \%$. How this data fits to Czech agrarian sector should be part of the further research. According to StatCounter global stats $(2017 b)$ a web browser use also differs. In the last 12 month the leading browser of the Czech Republic market is Chrome with $55.47 \%$, in the contrary Internet Explorer has just $7.77 \%$ of the market. In case where the portal eAGRI will be modernized in terms of usability for mobile devices, it will also need to take potential problems with the implementation of modern methods and technologies into account.

Other analysis lead us to the result that about $1 / 3$ 
of all visits and views are focusing on internal applications of the portal. This information is not a problem at all, on the other hand, there is more than one website which leads users to the same result and this causing inconsistency in the structure of the portal, user navigation and their potential confusion. Another potential problem we see is a lack of eAGRI branding. Still quite a lot of users use search engine when they need to reach internal applications of the portal instead of the eAGRI home page or URL which lead to these application directly.

We are not clear about eAGRI strategy in Social Networks and Email marketing, but on the basis of the data obtained, it can be stated there is none or only random.

\section{Five second test}

None of testers knew what kind of website they will evaluate and each tester tested the objective web page independently. All tests were performed in the usability lab. We formed 2 groups of testers each containing 5 testers. Due to maintain comparability of results with studies conducted by Benda et al. (2016) and the first group of testers tested the home page of eAGRI portal - eagri. cz/public/web/mze/. After 5 second testers spent on this page we asked them to simply describe what they saw and what are they able to find on the page. We asked them if they are familiar with the eAGRI portal also.

1. Tester - identified eAGRI logo, Minister of Agriculture image and information about African swine fever, which is actual and leading information in the web page carrousel. The tester tagged this page as online information newsletter from agrarian sector. To the question whether this site has the tester visited previously tester responded negatively.

2. Tester - identified eAGRI logo, Minister of Agriculture image and information about African swine fever. The tester also noticed carousel with images about farming in the middle of the web page. The tester tagged this page as information page about farming. The tester was not familiar with eAGRI portal.

3. Tester - identified eAGRI logo, information about African swine fever and some of menu items. The tester tagged this page as a web page dedicated to hunters or farmers. The tester was not familiar with eAGRI portal.
4. Tester - identified eAGRI logo and Marian Jurečka as s Secretary of State, because this text information is presented on the website too close to the minister photo and the visual arrangements of this information is misleading. Tester also described some menu items and news. Tester tagged the web page as a service for information portal for farmers. The tester was not familiar with eAGRI portal.

5. Tester - identified eAGRI logo and described all the tested web page as a portal dedicated to inform farmers and wide audience about agriculture sector. He described himself as a brother of a farmer which is quite familiar with the content and also internal applications.

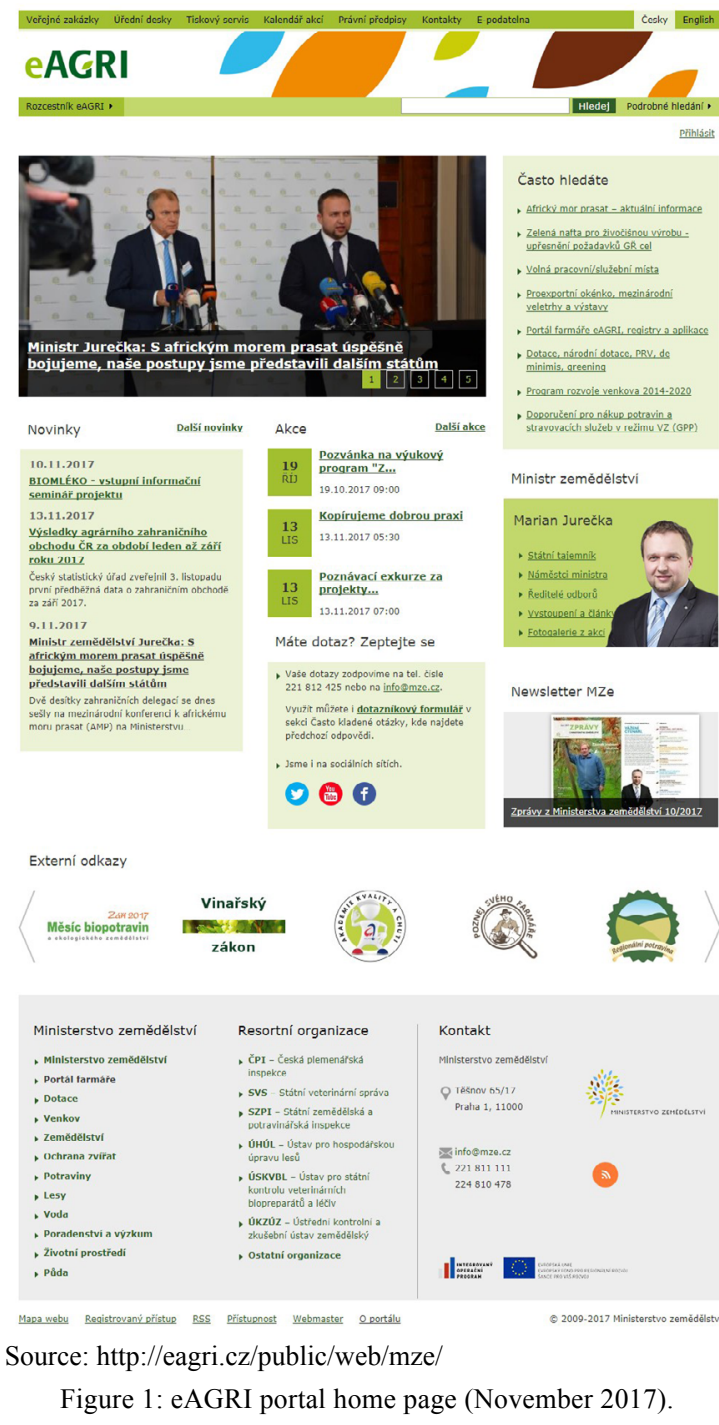

Overall, none of the testers except the fifth one were able to combine the eAGRI logo with the Ministry of Agriculture of the Czech 
Republic and they also did not know the brand. Compared with the study from year 2016 conducted by Benda et al. (2016) the results are very similar. From this, it can be judged that there were no improvements in the eAGRI portal home page during the year 2017.

The second group of testers tested different web page of eAGRI portal. This page was an event calendar - eagri.cz/public/web/mze/kalendar-akci/. After 5 seconds on a web page all 5 users have to respond to the same questions like previous group.

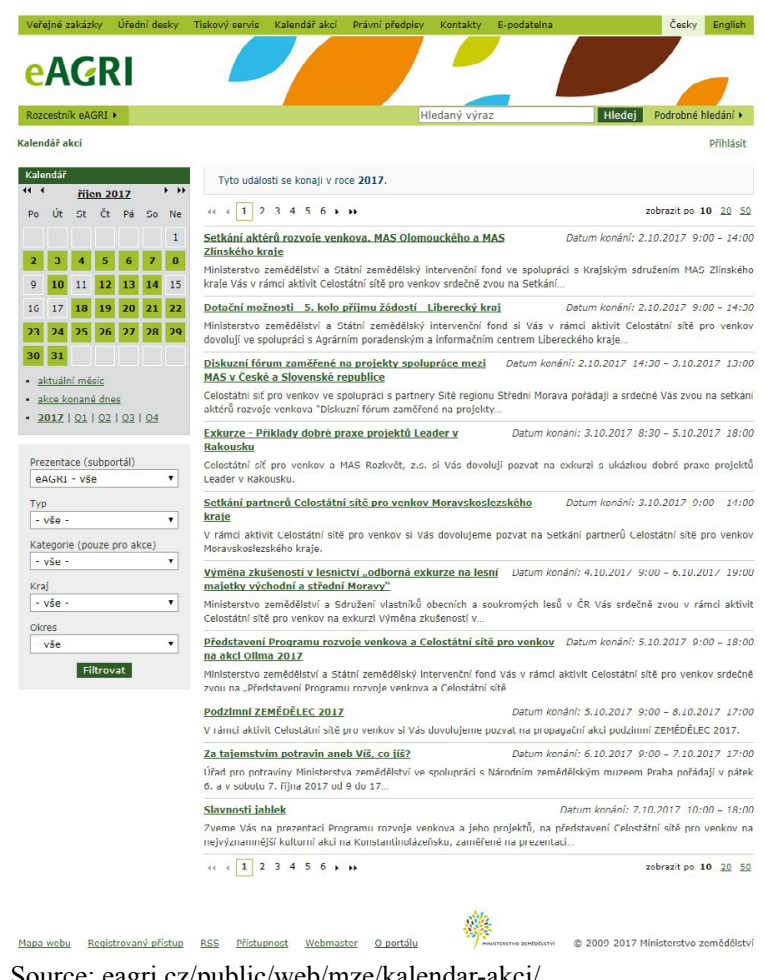

Source: eagri.cz/public/web/mze/kalendar-akci/

Figure 2: eAGRI event calendar page (November 2017).

1. Tester - identified eAGRI logo and tagged the web page as an event calendar in year 2017.

2. Tester - identified eAGRI logo and described some events. The tester tagged the web page as informing channel about agricultural events.

3. Tester - was not able to perform results after only 5 seconds on the web page.

4. Tester - identified eAGRI logo. Tester was not able to tell what the web page is about.

5. Tester - identified eAGRI logo, some menu items and information about events in year 2017. Tester tagged the web page as an events calendar for workers in agriculture based on events information.
None of the testers mentioned the previous knowledge of the eAGRI portal. None of the testers were able to combine the eAGRI logo with the Ministry of Agriculture of the Czech Republic and they also did not know the brand. The results of the correct classification of a portal content in the overall context on this page are even worse than in previous group. The web page tested by this group is full of text, less clear, and does not contain any significant points that the tester's eyes could focus on.

Overall, on the basis of the tests made, the identification of the portal itself is insufficient. The incoming user is not informed about the web page visited and eAGRI brand should also describe its meaning more. Also the combination of information for professionals and general public does not seem appropriate. Both of those groups seeking different kind of information and if the portal should serve both, these information should be divided.

\section{Thirty second test}

For the purpose of this test we formed 2 groups of testers 5 users each again. These testers were different people than in groups that tested during Five second test. After the 30 second they spent on objective web pages we ask them the same question like after the Five second test. Like the first group in Five second test, the first group of tester tested the home page of eAGRI portal eagri.cz/public/web/mze, this time for 30 seconds.

Again, the results are close to the results of a study done by Benda et al. (2016). After 30 seconds the testers spent on the web page, all of them were able to describe the purpose of the web page and its operator, the Ministry of Agriculture of the Czech Republic. All five testers found this information in the footer of the web page. Four testers tagged the web page as an information portal about the agriculture. One tester tagged the web page as a portal for farmers and workers in agriculture. This tester also mentioned his previous knowledge of the portal, because his job in the forestry area. But we can point out that description of the portal by this user is not so accurate.

The testing performed by the other group was more controversial. The second group tested the same page with the event calendar eagri. cz/public/web/mze/kalendar-akci/ as well as the second group during the Five second test. One tester tagged the web page as an internal event calendar for employees of Ministry of Agriculture. The reason was the logo at the bottom of the web 
page and events description. Two testers identified themselves as a farmer and employee of the Agroholding company. Both identified web page based on logo as a part of the large portal which focusing on agrarian information for all the Czech people. Two last testers tagged the web page identically as a tool for sorting and displaying calendar and events in agro-business and agriculture from the Ministry of Agriculture of the Czech Republic. Those testers had no previous experience with the portal.

Despite the fact that the second tested web page is the part of the same web portal, it looks different and for example footer is also different than on the home page. This fact can again lead to confusion of the users. In 30 seconds all testers should identify the main and key purpose of the tested web page clearly. If they are not able to do so, than we can identify significant problems with usability.

\section{Heuristic evaluation}

All the complex Heuristic evaluation analysis goes beyond the scope of this article. We would like to provide information on whether or not the heuristics are met using the Table 1 and the comments below. For our analysis we used the list of heuristics created by Nielsen (1991). The study was performed by one usability expert. Heuristics and results are presented in Table 1.

The data in the table shows that the verified heuristics are not met. The reason is in particular the inconsistency of the portal, mixing of information for different types of users, confusing navigation, irrelevant search results which are not lead to content with the entered keywords and many others. Undo and redo functions are not provided by the portal itself and have to be supplied just by the browser. There is no special Error 404 web page on the portal and some of internal links end by this result. The user is not informed about, how to solve this problem. In terms of internal applications there is inconsistent help and documentation provided but not in a useful way and often for the older versions of those applications and mainly in the form of non-online help.

The results of the Heuristic evaluation study correspond to the conclusions of Benda et al. (2016). From this point of view, it can be said that the eAGRI portal has not made any noticeable improvements in this respect.

\section{First click test}

This testing was performed by the same group of 5 testers which tested the home page of eAGRI portal - eagri.cz/public/web/mze during the Five second test. The main purpose of this testing was to analyze whether testers are able to identify key navigation parts of a web page and use them to achieve their goals. Those goals were:

1. Find contacts to the Ministry of Agriculture of the Czech Republic;

2. Use internal Search tool;

3. Find the application "Portal of a farmer";

4. Find information about Regional food.

All testers were able to meet the goals and click to the proper part of the document. Some of them needed a noticeable time to achieve the goal, but the time was not measured during this study.

\begin{tabular}{|c|l|l|c|}
\hline No. & Description & Recommendation & Results \\
\hline 1. & Visibility of system status & provide a feedback of the system in reasonable time & $\mathrm{N}$ \\
\hline 2. & $\begin{array}{l}\text { Match between system and the real } \\
\text { world }\end{array}$ & use language familiar to the user, information in a natural and logical order & $\mathrm{Y}$ \\
\hline 3. & User control and freedom & help user to deal with mistakes and turns, support undo and redo & $\mathrm{N}$ \\
\hline 4. & Consistency and standards & follow the convention, use consistent styles and actions & $\mathrm{N}$ \\
\hline 5. & Error prevention & $\begin{array}{l}\text { eliminate errors and prevent problems, ask for confirmation before } \\
\text { complicated tasks }\end{array}$ & $\mathrm{N}$ \\
\hline 6. & Recognition rather than recall & $\begin{array}{l}\text { make options visible, don't force user to remember information about } \\
\text { different parts of a dialogue }\end{array}$ & $\mathrm{N}$ \\
\hline 7. & Flexibility and efficiency of use & system with options for inexperienced and experienced user & $\mathrm{N}$ \\
\hline 8. & Aesthetic and minimalist design & only insert important and relevant information in dialogues & $\mathrm{N}$ \\
\hline 9. & $\begin{array}{l}\text { Help users recognize, diagnose, } \\
\text { and recover from errors }\end{array}$ & indicate the problem and suggest a solution & $\mathrm{N}$ \\
\hline 10. & Help and documentation & $\begin{array}{l}\text { provide help and documentation with the easy access to information and } \\
\text { logical structure }\end{array}$ & $\mathrm{Y} / \mathrm{N}$ \\
\hline
\end{tabular}

Source: Nielsen (1991), adapted by authors 
At the same time, some findings need to be emphasized. Two testers found Contacts - Goal no. 1 in the menu. Three others in the footer. None of the tester used the menu item "eAGRI Signpost" despite the fact this is the key navigation part of the portal and for example leads to the internal applications and other main parts of the eAGRI portal. All testers navigate during the goal no. 3 just by the link in the footer. The last goal took testers the largest amount of time. The most of them tried upper menu before they read the whole content of the web page, where is also a link to Regional food information external web site provided.

\section{Discussion}

All performed studies, tests and analysis focused on the general public. General public are all average users with average equipment and with their need to perform whatever they like on the eAGRI portal, navigate anywhere they want to, how they want to and, moreover, to land from outside on any web page of the portal structure. Results of the Analysis of Google Analytics data shows that almost $1 / 3$ of all portal users seems to be professionals in agrarian sector. Taking this into account it is obvious that it would be appropriate to perform a study of ergonomics which will be focused mainly on this group of users. But this group of users is just the part of the mentioned general public. The age structure of the agricultural population is described by Ministry of Agriculture CR (2015b): In the $4^{\text {th }}$ quarter of $2015,45-59$ years old employees $(42.3 \%)$ were in the agrarian sector of the Czech Republic, followed by workers aged $30-44$ (35.6\%). Lower earning workers were 15-29 years old (11.2\%) and older workers, i.e. aged 60 and over (10.9\%). Studies conducted by for example Shamim et al. (2016) and Righi et al. (2017) show that there the age was found to be significant for visual appeal, comprehensiveness, intuitiveness, and pre-knowledge requirement but there is also no need to focus on design for older people but focus on the useful and also usable design for an average user. And not only in the way of ergonomics, usability and design, but also in the social role.

\section{Conclusion}

In this paper, we presented results of several usability methods applied on the eAGRI portal which report unflattering results. The main task was to find out if the ergonomic level of the portal is sufficient or not. A partial goal was to compare the findings from a previously conducted study by Benda et al. (2016). The results of all analyzes show that the overall ergonomics of the portal is not at a satisfactory level and that there is no significant improvement on the portal in the last year. The reason for poor results is in particular the inconsistency of the portal, mixing of information for different types of users, confusing navigation, irrelevant search results which are not lead to content with the entered keywords and many others. Users are not able to understand the purpose of the portal or namely the landing web page, because the portal does not offer this information easily in 5 or even in 30 seconds. Due to the portal structure it is not clear if the eAGRI portal truly knows its purpose goals and focus. This brings us to the same conclusion as Ulman et al. (2017) presented as a result of their research: "The provision and user experience of agricultural e-government services must be improved by the Ministry of Agriculture to improve the services quality". To find the purpose and focus of the eAGRI portal should be the very first step of the Ministry of Agriculture of the Czech Republic to improve the ergonomics quality of the portal and provide users with the convenience in using the portal.

\section{Acknowledgements}

The results and knowledge included herein have been obtained owing to support from the following institutional grants. Internal grant agency of the Faculty of Economics and Management, Czech University of Life Sciences in Prague, grant no. 20171008, „Acquisition, processing and evaluation of data obtained from laboratory testing of software usability and user experience“.

Corresponding author:

Ing. Petr Benda, Ph.D.

Department of Information Technologies, Faculty of Economics and Management

Czech University of Life Sciences Prague, Kamýcká 129, Prague 6 - Suchdol, 165 00, Czech Republic

Phone: 00420224382 278,E-mail: bendap@pef.czu.cz 


\section{References}

[1] Bartneck, C. and Rauterberg, M. (2007) "HCI reality - an 'Unreal Tournament'?“, International Journal Of Human-Computer Studies, Vol. 65, No. 8, pp. 737-743. ISSN 1071-5819. DOI 10.1016/j.ijhcs.2007.03.003

[2] Benda, P., Šmejkalová, M. and Šimek, P. (2016) "Usability Analysis of Agricultural Portal eAGRI in Terms of the General Public", AGRIS on-line Papers in Economics and Informatics, Vol. 8, No. 4, pp. 15-23. ISSN 1804-1930. DOI 10.7160/aol.2016.080402.

[3] Carrol, J. M. (2003) "HCI models, theories, and frameworks: toward a multidisciplinary science", San Francisco, Morgan Kaufmann. The Morgan Kaufmann series in interactive technologies. 551 p. ISBN 1-55860-808-7.

[4] Carroll, J. M. and Rosson, M. B. (2009) "Scenario based design", Human Computer Interaction, edited by Andrew Sears, \& JulieA. Jacko. Boca Raton: CRC Press. pp. 145-162. ISBN 9781420088892.

[5] Doncaster, P. (2014) "The UX Five-Second Rules: Guidelines for User Experience Design's Simplest Testing Technique“. Elsevier Inc., pp. 108. ISBN 978-012800534-7.

[6] Geisen, E. and Bergrstrom, J. R. (2017) "Usability testing for survey research“, Cambridge, MA: Morgan Kaufmann Publisher, an imprint of Elservier. ISBN 9780128036563.

[7] Giacomin, J. (2014) "What Is Human Centered Design?", The Design Journal, Vol. 17, No. 4, pp. 606-623. ISSN 1460-6925. DOI: 10.2752/175630614X14056185480186.

[8] Google (2017) "Improve the customer experience with digital analytics“, Google Analytics Solutions [Online]. Available: https://www.google.com/analytics/analytics/ [Accessed. 28 Sept 2017]

[9] IEA (2017) "Definition and Domains of Ergonomics", IEA: International Ergonomics Association [Online]. Available: http://www.iea.cc/whats/ [Accessed. 26 Sept 2017].

[10] ISO 6385:2016 (2016) "Preview Ergonomics principles in the design of work systems“, Geneva, Switzerland: International Organisation for Standardisation.

[11] ISO 9241-210:2010. (2010) "Human-centred design for interactive systems“, Geneva, Switzerland: International Organisation for Standardisation.

[12] ISO/FDIS 9241-11 (2017) "Ergonomics of human-system interaction -- Part 11: Usability: Definitions and concepts“. [Online]. Available: https://www.iso.org/standard/63500.html [Accessed: 27 Sept 2017].

[13] ISO 9241-11:1998 (1998) "Preview Ergonomic requirements for office work with visual display terminals (VDTs) -- Part 11: Guidance on usability“, Geneva, Switzerland: International Organisation for Standardisation.

[14] Krug, S. (2006) “Don't make me think!: a common sense approach to Web usability", 2 $2^{\text {nd }}$ ed., Berkeley, Calif, New Riders Pub., ISBN 03-213-4475-8

[15] Lindgaard, G., Fernandes, G., Dudek, C. and Brown, J. (2006) "Attention Web Designers: You Have 50 Milliseconds to Make a Good First Impression!", Behaviour \& Information Technology, Vol. 25, No. 2, pp. 115-126. ISSN 0144-929X. DOI 10.1080/01449290500330448.

[16] Ministry of Agriculture CR. (2015a) “About eAGRI“, Ministry of Agriculture of the Czech Republic [online]. Available: http://eagri.cz/public/web/en/mze/about-eagri/ [Accessed: 19 Oct 2017].

[17] Ministry of Agriculture CR. (2015b) „Zelená zpráva 2015 (Green Report 2015-in Czech)“, Ministry of Agriculture of the Czech Republic. [Online]. Available: http://eagri.cz/public/web/file/481729/ ZZ15_V4.pdf, [Accessed: 18 Oct 2017]

[18] Molich, R. and Nielsen, J. (1990) "Improving a human - computer dialogue", Communications of the ACM, Vol. 33, No. 3, pp. 338-348. ISSN 1557-7317. DOI 10.1145/77481.77486.

[19] Nielsen, J. (1991) "Usability metrics and methodologies", ACM SIGCHI Bulletin, Vol. 23, No. 2, pp. 53-69. ISSN 0736-6906. 
[20] Nielsen, J. (1993) “Usability engineering”, $1^{\text {st }}$ ed., Boston: AP Professional, ISBN 01-251-8406-9.

[21] Righi, V., Sayago, S. and Blat, J. (2017) "When we talk about older people in HCI, who are we talking about? Towards a 'turn to community' in the design of technologies for a growing ageing population“, International Journal of Human-Computer Studies, Vol. 108, pp. 15-31. ISSN: 1071-5819. DOI 10.1016/j.ijhcs.2017.06.005.

[22] Rogers, Y. (2012) "HCI Theory: Classical, Modern, and Contemporary", Synthesis Lectures On Human-Centered Informatics, Vol. 5, No. 2, pp. 1-129. ISSN 1946-7699. DOI 10.2200/S00418ED1V01Y201205HCI014.

[23] Rusu, C., Rusu, V., Roncagliolo, S., and González, C. (2015) "Usability and User Experience“, International Journal Of Information Technologies And Systems Approach, Vol. 8, No. 2, pp. 1-12. ISSN 1935-5718. DOI 10.4018/IJITSA.2015070101.

[24] Sauro, J. (2011) "Getting the First Cllick right", Measuring U. [Online]. Available: https://measuringu.com/first-click/. [Accessed: 28 Sept 2017].

[25] Shamim, A., Balakrishnan, V., Tahir, M., and Ahsan, Q. M. (2016) "Age and domain specific usability analysis of opinion visualisation techniques", Behaviour \& Information Technology, Vol. 35, No. 8, pp. 680-689. ISSN 1362-3001. DOI 10.1080/0144929X.2016.1141235.

[26] Singleton, W. T. (1982) "The Body at work: biological ergonomics", $1^{\text {st }}$ ed. New York: Cambridge University Press. ISBN 9780521240871.

[27] StatCounter Global Stats. (2017a) "Desktop vs Mobile vs Tablet Market Share in Czech Republic" StatCounter Global Stats. [Online]. Available: http://gs.statcounter.com/platform-market-share/ desktop-mobile-tablet/czech-republic. [Accessed. 2 Nov 2017]

[28] StatCounter Global Stats. (2017b). „Browser Market Share in Czech Republic“ StatCounter Global Stats [Online]. Available: http://gs.statcounter.com/browser-market-share/all/czech-republic [Accessed. 2017-11-02]Tomlin, C. (2014) „5 Second Test: An important conversion optimization tool“, Useful Usability [Online]. Available: http://www.usefulusability.com/5-second-test/, [Accessed. 2017-09-27]

[29] Ulman, M., Jarolímek, J., Šimek, P. and Tyrychtr, J. (2017) "Quality in use evaluation of online services: a case of the eAGRI portal in the Czech Republic", Proceedings of the Conference Agrarian Perspectives XXVI, Prague, pp. 417-424. ISBN 978-80-213-2787-0.

[30] Weinmann, M., Schneider, Ch. and Brocke, v. J. (2016) "Digital Nudging", Business \& Information Systems Engineering, Vol. 58, No. 6, pp. 433-436. ISSN 2363-7005. DOI 10.1007/s12599-016-0453-1.

[31] Zhang, P. and Li, N. L. (2005) "The intellectual development of human-computer interaction research: A critical assessment of the MIS literature (1990-2002)," Journal of the Association for Information Systems, Vol. 6, No. 11, pp. 227-292. ISSN 1536-9323. 